\title{
The Combat Training Damage Control under the Condition of the Existing Problems and Countermeasures Research
}

\author{
Xinjie Zhang ${ }^{1, a}$ and jie Yue ${ }^{2, b}$ \\ ${ }^{1}$ Department of Surface Ship Command, Dalian Naval Academy, Dalian, 116018, China \\ Unit 91278 Dalian, 116018, China \\ 446982051@qq.com,gku94852@tom.com
}

Keywords: The combat training; Vessel damage control; Countermeasures

\begin{abstract}
. since the combat training, especially the damage control simulation training equipment put into use, the forces of damage control to improve training level had the very big margin, but some still exist in the training from actual combat environment requires a gap problem, this paper respectively from commander, individual and damage control training facilities research and exploration on the three aspects.
\end{abstract}

\section{Introduction}

On March20, 2014, issued by the central military commission on raising the level of the military training the combat opinions opened the prelude of army combat training. Vigorously strengthen the combat training, has become our army military training important gripper reality problem. So-called the combat training is the criteria on the needs of actual combat, in mission task for traction, under the condition of approximation of actual combat, rule against rival warfare, operational principles and the possibility of change, put forward the operational needs, and targeted training. Informally, it is "how to play, they how to practice", the essence of which is "war is what kind, what training is, need to practice what you war." Ships as a maritime mobile combat platform, in naval ships once hit will cause significant casualties, will affect the morale of morale. Timely and correctly implement damage control, is to keep warships fighting capacity, life protection personnel, complete combat mission important guarantee. Due to independent closed vessels, slight damage in battle the butterfly effect is formed within the system easily, cause serious interference to combat actions, even lose their combat capability. How to limit damage to live, or even eliminate in damage control training is we should research the problem.

\section{The Definition of Vessel Damage Control}

Vessel damage control, hereinafter referred to as damage control, it is the floorboard of the activities of all vessels, vessels vitality. Also can be said to be the vessel to maintain or restore vitality of measures and actions to prevent, restrict and eliminate damage. Mainly includes the damage control command, injury prevention, flooding, fire, damage control equipment, nuclear weapons, chemical weapons (biological) attack damage control, under the condition of aid wrecked ship, damage control training, damage control equipment configuration and management, etc.

Ships vitality means all types of vessels to resist breakage disasters, maximum limit to maintain and restore its navigation and combat capability. In the process of resistance to all kinds of damage mainly for three aspects: one is to try to prevent and avoid the damage of disasters occur, or makes the possibility of disaster damage to a minimum; Second, after the disaster damage, to limit the spread of the disaster damage spread; Third, on the basis of the limit, as soon as possible to eliminate adverse effects generated by the breakage of disasters.

Ensure ships vitality is the common responsibilities of all the crews. When the vessel damage, how under the correct command commander of all the crews together to eliminate limit damage form, to ensure the vitality of ships and its operational functions is we need to study damage control in the usual training content. 


\section{The Content of the Vessels Damage Control Training}

Ships belong to common damage control training course training, all the crews must all take part in, and during the entire service or intermittent.

Vessel damage control training purpose is to make all levels of staff to grasp the correct using method of damage control command, damage control equipment such as knowledge; Trained crews in various conditions and a rapid accurate and effective implementation of damage control in wartime, and even creative behavior to eliminate the vessel damage, restore naval battle effectiveness and vitality.

Vessel damage control training contents include the following content of the prescription:

(1) The ships structure, cabin arrangement

(2) The methods of use of damage control equipment

(3) The damage control basic practice research

(4) Each department each fighting positions and radar personnel action coordination study

(5) To leak, fire, repair damaged weapon system research and technology

(6) Vessel command post and damage control command post training of damage control command

(7) The compatibility study of personnel

(8)On the part of the casualties and under the condition of ship pollution damage control research

(9)And the preparation of damage control within the organization's monthly training (light diving team, outboard leak, damage control stance, ship balance group, etc.)

(10)For all the fighting and service department mutual action of damage control combat exercises and practice

\section{The Combat Training under the Condition of Damage Control Problems Existing in the Training}

2014 units according to the navy standard, this ship's damage control plan for the "real" optimization, especially training simulation equipment put into use, damage control training level had the very big margin improvement. But there are still some problems in practical training such as: individual soldiers damage control training is short weaknesses, commander command damage control exercises routing, back-to-back training false problem. To some extent, restricted the ability of the radar comprehensive damage control.

Commander Training Is Not Enough; the Ship Commander's Ability to Conduct Damage Control Is Weak. Ships (deputy) with department long yes commander in damage control. Because of the limitation of training conditions in the usual damage control training, no practice good command ability, once the vessel is damaged, will panic, difficult damage control to take effective measures to ensure the safety of ships. Specific performance in the following aspects:

(1)Cabin on the ship structure and damage control

Facilities are not familiar with. Part one is the ship commander cabin on the ship only know the main cabin structure distribution, and for some none to cabin, spray tank, ballast tank, bottom and cofferdam usually use fewer compartments are not familiar with. As the large surface ships service, accommodation, the phenomenon of "not familiar" are more likely to happen. When there is damage of ships, the commander will be at a loss, the command is not timely, the command is not accurate, due to time delay, operational errors, endanger the safety of the ship. 2 it is to ship part of the commander of this ship the location of the damage control equipment, performance, quantity, etc. Are not familiar with. Such as the location of the drainage system, drainage capacity, pourable cabin position influence on ship insubmersibility, etc. If the damage control equipment are not familiar with, in the implementation of damage control command, can't scientific distribution of damage control power, will also delay the timing of the damage control, cause the damage to the vessel vitality.

(2)Damage control lack of practical experience 
It is difficult to effectively organize direct damage control training. Vessel damage control training under the simulation status, with the actual situation of ship damage may occur during the war. Commander of naval ships might happen in the actual damage to the lack of perceptual knowledge, as it should be no tilt, heeling, mostly under the condition of the fire command experience, not to mention the command ship actual damage control experience, in ship damage control training for granted, by the imagination, the lack of a scientific and effective measures.

(3)Lack of awareness of damage control training

More attention at ordinary times the leadership of the ship safety management, supervise and urge the jackboots strictly implement safety regulations and precautions are in place, but the lack of awareness of the seriousness of possible damage in wartime, the sense of urgency is not strong, the study of damage control training is not enough, that damage control training just to do well the training. Once the ship damaged during the war, the lack of effective measures, causing damage to expand, affect the completion of mission.

(4)"back-to-back" organization mechanism is not sound, is difference from the actual battlefield environment.

The so-called "back-to-back" training refers to the commander unwitting conditions is issued at the bottom of the plot, strain capacity of the main training commanders. Plot in training appraisal of published also often takes the form of "back to back", but looking from the implementation situation, want to set the plot and the training plan is the same as the ship to use, not to achieve the effect of training commander emergency disposal capability.

Individual Damage Control Skills Have Short Board Weaknesses. Now ship unit for damage control training, for assessment of study subjects more attention, such as collision, indoor extinguishing fire, outdoor, etc. Not enough with the examination subjects, such as damage control group training, disaster investigation, training, maintenance skills training. Training short even items, to cope with the complexities of sea in the future a lack of proper preparation, mainly manifested in the following aspects:

(1)Vessel damage control team training does not reach the designated position, professional personnel damage control ability to reach the combat requirement.

Such as ship light diving team training, training time keeping ability each year to reach regulation, division every two years or more units are centralized organization training new part-time diver. Because of the limitation of training conditions, it's hard to do a lot of units. Undermine the tube station personnel quality is not high, mostly young, sometimes in order to gather together, catch a new comrade hold temporarily. Damage control fighting positions is the damage control on the ships assault force, they ability strong and the weak damage control disposal effect of radar has a pivotal role, but looked from the reality, its damage control ability is not very satisfactory.

(2)Disaster investigation of serious lack of training.

For damage control decision, is very important to obtain complete information accurately. In general, in disaster information on the latest fighting positions will timely report to the decision makers, but the damage occurs, complicated and changeful, decision-makers timely and accurately complete the possibility of disaster information is greatly reduced. Many ships because the damage locations without timely and accurately, bungled disposal opportunity, caused a great loss. Army training in disaster investigation now exist are few in number, lack of professional training venues and facilities.

Holdings to repair damage to weapons and technology system research is not enough. Now mainly operating skills training, the lack of corresponding training mechanism of maintenance skills, only by the empirical study to cultivate yachts far cannot achieve the requirement of equipment development now, once have been damaged during the war, people lack of application maintenance skills, combat power cannot get quick recovery, affect the overall effectiveness of the ship.

Vessels Damage Control Research Is Not Enough. Vessel damage control is system engineering, through the design, production and service of each link. Only pay special attention to each link management, to ensure the safety of the ship the whole life. 
(1)Vessels in structural design and manufacture link protection need to be further strengthened.

As some of the old type ship some problems sealing undead cabin, some cabin space limit accessibility for maintenance and damage control is not enough, some of the design of the valve the problem of unreasonable power plant life force is not strong and so on.

(2)The maneuverability of the solution plans need to be further enhanced.

After the new syllabus issued, each unit to modify and perfect the project plan, but there is still a vague language problems, solution plans have not done "five w" (what people, what time, where, what, to what extent) requirements. Damage control exercises, practice together, practice consciousness, mainly in composition, not practical enough.

(3)Ships, under the condition of nuclear, chemical, raw attack damage control research was not enough.

Nuclear, chemical, biological vessel damage control under the condition of how to implement, power plant, how to use the engine room personnel how to protection, these aspects to be fastidious.

(4)Not enough scientific appraisal system.

Now the damage mainly adopt the training and examination methods of control JiaoLianShi appraisal way, commander with ordinary crews examination subjects, same one-pot, not enough scientific appraisal way, the lack of a level difference.

\section{The Combat Training under the Condition of Damage Control Training Countermeasures}

In View of the Ship Commander Damage Control Training Content Clearly, Intensify Commander Training. All ship type to write commander damage control manual work, specific content, regular check, solve the commander cabin structure are not familiar with, damage control facilities are not familiar with.

(1)Intensify JiaoLianShi damage control inputs.

Best based on naval training center, the establishment of damage control training vessel, improve the commander of the actual damage to the vessel might occur perceptual knowledge, enhance commander in tilt, heeling, under the condition of the fire command.

(2)Rich simulation method, and improve the training effect.

Rich simulation method on the premise of safety, to improve the realistic effect of simulation environment, improves the enthusiasm of training.

(3)Ensuring greater damage control "back-to-back" study and carry out the training, improve the level of radar damage control.

"Back-to-back" training can ship commander strain capacity; can also train the jackboots of damage control basic operation skills. "Back-to-back" training is not blind random number, but by the training team to develop a reasonable training plan, in the other crews (including ship commander) don't even know what a scheme under the situation of the training content, the plot is given according to the time node individually. Training team can also be in the annual training to develop more set of feasible solution, randomly before the training. Content should be covered as far as possible each fighting positions, each damage type, organic reasonable collocation. To damage control basic operation personnel, requirements as much as possible the use of all kinds of damage control equipment include the standard equipment.

Improve Individual Damage Control Skills. (1) Explicitly in the training program of damage control team skills requirements, incorporated into the training program evaluation system.

Training program is the basis of military training, plays a leading, coordination, command, control, training, skills requirements and assessment criteria for the damage control team can take the form of attachment in the new outline.

(2) Relying on damage control training ship to strengthen disaster investigation.

Can also set the plot in damage control training ship to scout for reconnaissance in all kinds of complex situations, special strength have smoke case investigation practice.

(3) Requires increasing repair damage weapons and technology system research, establish maintenance skills training system. 
Establish noncommissioned officers to the repair shop training system, training department to factory regulation, according to the training program specified in the technical level training for pilot training.

Scientific Research Units, Manufacturers, Ship Unit Force Increase the Study of Ship Damage Control. (1)Vessels in the design of production to strengthen the structural protection.

Ships of damage control in the design of consideration and wartime damage control can greatly increase the warships combat capability. For national army in the process of ship design, the damage control and warship protective and consideration, even sacrificing some capabilities to ensure that damage control design. Should set up their own ships safety appraisal department, to prepare to build and into battle ship structural protection index appraisal, determine whether meet the requirements of indicators.

(2)Strengthening scheme plan of feasibility study.

Same type ships training backbone together, further refinement, the specific scheme plan, improve the operability, avoid two members of the opposite sex, really make a feasible scheme of "real" plan.

(3)Joint multilateral force of vessels under the condition of nuclear, chemical, biological research of damage control.

Build a communication platform, research institutes, factory, ship unit organize regular ship nucleation related seminars, research results issued to ship unit.

(4)Set up comprehensive evaluation system of damage control.

Assessment of damage control can be divided into two parts, theory and practice. Theory of individual assessment, commander of examination of two levels. Damage control can be divided into individual damage control skills of examination implements, commander, damage control organization of examination and assessment of radar four levels, finally take a weight together.

\section{References}

[1] J.Dezert.Foundations for a new theory of plausible and paradoxical reasoning [J].International Journal Information and Security, 2002, 9:13-57.

[2] J. Dezert, F. Smarandache.Partial ordering of hyper-powersets and matrix representation of belief functions within DSmT[C].Proceedings of The 6th Int. Conf. on Information Fusion, Australia, Queensland, 2003:230 2003.

[3] Jøsang, M. Daniel, P. Vannooren berghe.Strategies for combing conflicting dogmatic beliefs[C].Proceedings of The 6th Int. Conf. on Information Fusion,Australia,Queensland,2003:1133 1140.

[4] M. Daniel. Distribution of contradictive belief masses in combination of belief functions. Information, Uncertainty and Fusion [M]. Academic Publishers, 2000.

[5] F. Smarandache,J. Dezert. Proportional conflict redistribution rules for information fusion. Applications and Advances of DSmT for Information Fusion (Collected works)[M]. American Research Press, 2006.

[6] F. Smarandache, J. Dezert.A Simple Proportional Conflict Redistribution Rule [J]. International Journal of Applied Mathematics \& Statistics, 2005, 3 (5):1-36.

[7] G. Dissanayake,P. M. Newman et al. A solution to the simultaneous localization and map building (SLAM) problem [J]. IEEE Trans. Robotics and Automation, 2001, 17(3):229-241.

[8] Zhou Shizhong. Foreign naval military training methods of the reform and development [J]. Journal of world naval training, 2005 (4). 